\title{
BMJ Open Night shift work, long working hours and dementia: a longitudinal study of the Danish Work Environment Cohort Study
}

\author{
Kirsten Nabe-Nielsen, ${ }^{1}$ Åse Marie Hansen, ${ }^{1}$ Kazi Ishtiak-Ahmed, ${ }^{1}$ \\ Matias Brødsgaard Grynderup, ${ }^{1}$ Finn Gyntelberg, ${ }^{2}$ Sabrina Islamoska, ${ }^{1}$ \\ Erik Lykke Mortensen, ${ }^{1,3}$ Thien Kieu Thi Phung, ${ }^{4}$ Naja Hulvej Rod, ${ }^{1}$ \\ Gunhild Waldemar, ${ }^{4}$ Rudi G J Westendorp, ${ }^{1,3}$ Anne Helene Garde ${ }^{2}$
}

To cite: Nabe-Nielsen $\mathrm{K}$, Hansen ÅM, Ishtiak-Ahmed K, et al. Night shift work, long working hours and dementia: a longitudinal study of the Danish Work Environment Cohort Study. BMJ Open 2019;9:e027027. doi:10.1136/ bmjopen-2018-027027

- Prepublication history for this paper is available online. To view these files please visit the journal online (http://dx.doi org/10.1136/bmjopen-2018027027).

Received 3 October 2018 Revised 11 January 2019 Accepted 12 February 2019

Check for updates

(c) Author(s) (or their employer(s)) 2019. Re-use permitted under CC BY-NC. No commercial re-use. See rights and permissions. Published by BMJ.

${ }^{1}$ Department of Public Health, University of Copenhagen, Copenhagen, Denmark ${ }^{2}$ National Research Centre for the Working Environment, Copenhagen, Denmark ${ }^{3}$ Center for Healthy Aging, University of Copenhagen, Copenhagen, Denmark

${ }^{4}$ Danish Dementia Research Centre, Rigshospitalet, University of Copenhagen, Copenhagen, Denmark

Correspondence to Kirsten Nabe-Nielsen; nabe@sund.ku.dk

\section{ABSTRACT}

Objective Shift work and long working hours are potential risk factors for dementia, but previous studies on shift work, long working hours and dementia are sparse and their findings are conflicting. Therefore, we investigated the effect of night shift work and long working hours on dementia.

Design A longitudinal study.

Setting Denmark.

Participants 3435 occupationally active men and women from the general working population.

Methods Work schedule covered day work (reference) and shift schedules without/with night work. Working hours covered <27, 28-36, 37 (reference), 38-44, and $\geq 45$ hours/week. As the primary outcome, we used register-based information about dementia, and estimated incidence rate ratios (IRR) and 95\% $\mathrm{Cl}$. Estimates were adjusted for gender, age, psychosocial work factors and cardiovascular risk factors.

Results We identified 85 dementia cases during a mean of 9.8 years of follow-up. We found a positive, but statistically insignificant association between night shift work and dementia (IRR=2.01; 95\% Cl: 0.87-4.65). Post hoc analyses indicated that this was only due to a higher risk in permanent night workers (IRR=3.25; 95\% Cl: 1.35 7.83). The dementia risk was also significantly higher among participants working 38-44 hours/week (IRR=2.08; $95 \% \mathrm{Cl}: 1.11-3.90)$ compared with those working 37 hours/week. We found no indications of a higher risk of dementia in participants working $<37$ hours/week or $\geq 45$ hours/week.

Conclusion We did not find arguments that night shift work or long working hours increased dementia risk in general. However, we found a higher risk of dementia in specific subgroups, that is, permanent night workers and employees with moderately longer weekly working hours than the standard.

\section{INTRODUCTION}

There has been a rising awareness concerning the potential long-term effects of night shift work and long working hours on cognitive

\section{Strengths and limitations of this study}

- Register-based measures of dementia diagnoses and drugs used in dementia treatment.

- The assessment of exposure to shift work with and without night work.

- Potential bias due to selection into shift work and long working hours.

- Few dementia cases due to the age of the study participants and undetected dementia.

function, including dementia. Dementia is a chronic or progressive syndrome, characterised by a decline in multiple cognitive domains. ${ }^{1}$ The syndrome is caused by pathological processes in the brain, which are typically related to neurodegeneration or cerebrovascular dysfunction. ${ }^{12}$

Shift work (particularly night shift work) and long working hours may influence the risk of dementia through the effects of these exposures on cardiovascular risk factors, for example, health behaviors, ${ }^{3-6}$ which, in turn, influence cerebrovascular function and thereby the risk of dementia pathologies. ${ }^{2-4}$ Furthermore, night shift work and long working hours are consistently associated with disturbed sleep. ${ }^{7-9}$ Results from laboratory studies in mice and humans have shown the importance of sleep for cerebral clearance of metabolites such as amyloid or tau, ${ }^{10} 11$ which are hallmarks of Alzheimer's disease $(\mathrm{AD})$, the most frequent cause of dementia. Additionally, observational studies support an association between disturbed sleep and dementia. ${ }^{12-15}$

Apart from their effect on cardiovascular risk factors and sleep, night shift work and long working hours are also related to the job content and the psychosocial working 
environment. ${ }^{16-18}$ It is hypothesised that high cognitive demands, high job complexity and job control protect against cognitive decline and dementia. ${ }^{19} 20$ Therefore, psychosocial work factors could contribute to the potential effect of night shift work and long working hours on dementia.

Regarding shift work, one study found a higher dementia-related mortality among permanent evening workers and rotating shift workers with or without night work, ${ }^{21}$ and one study reported a higher risk of dementia in genetically susceptible individuals (Apolipoprotein E (APOE) $\varepsilon 4$-carriers) with more than 20 years of night shift work. ${ }^{22}$ Two studies did not find a higher dementia risk among shift or night workers. ${ }^{23} 24$ The only study on long working hours ( $\geq 45$ hours/week) and dementia did not find an association between the two. ${ }^{24}$

In light of the scarcity and inconsistency of these previous studies, the aim of the present study was to investigate if night shift work and long working hours increase the risk of dementia. To contribute to the existing knowledge, we used a longitudinal design, collected information about incident dementia, and differentiated between shift work with and without night work as well as short, standard or long weekly working hours. We used a sample encompassing both male and female employees from the general working population.

\section{METHODS}

\section{Study population and inclusion criteria}

We used data from the Danish Work Environment Cohort Study (DWECS, see Burr et $a l^{25}$ for details). In 1990, a random sample consisting of 9700 people aged 18-59 years was drawn from the Central Population Register. Of these, 8664 people were interviewed in 1990 (participation rate was $90 \%$ among eligible individuals). In 1995, an additional sample of 212 people was drawn among Danish residents not living in Denmark at the time of selection of participants for the 1990-survey (participation rate in this sample was 58\%). Informed consent was not required.

We used survey data from each participant's first participation in DWECS (ie, 1990 or 1995). We only included participants who turned 60 years during the study's follow-up period, which ended $31^{\text {st }}$ December 2016. Thus, only participants born in 1956 or earlier were eligible for inclusion. The reason was that dementia diagnoses registered among younger patients have shown to be unreliable compared with dementia diagnoses in older patients. ${ }^{26-28}$ Furthermore, to reduce the risk of reverse causation (meaning that sublicinal dementia affected selection into/out of shift work and long weekly working hours), only participants who were alive, not emigrated and free of dementia during the first 5 years after participating in the survey were eligible for inclusion (figure 1). The design of the study is depicted in figure 2.

To be included in the study, participants had to have provided valid information about the duration of their education, whether they had shift work and/or the number of weekly working hours. In total, 41 participants were missing on education. A large number of participants were missing on shift work and working hours $(n=1518)$ mainly because they were out of the labour market at the time of the survey (eg, unemployed or on disability pension).

After applying these criteria, the final sample consisted of 3339 participants for the analyses of shift work and 3414 participants for the analyses of long working hours.

\section{Patient and public involvement}

Neither patients nor the public were involved in the present study.

\section{Assessment of dementia}

Information on dementia was obtained from The Danish Psychiatric Central Research Register ('Psychiatric Register'), The Danish National Patient Register ('Patient Register'), The Danish Register of Causes of Death ('Death Register') and the Danish National Prescription Registry ('Prescription Registry'). The Psychiatric Register was established as an electronic database in 1969, and from 1970, all psychiatric hospitals and psychiatric departments were obliged to report to the register. From 1995, outpatient treatment and emergency room contacts were also included. ${ }^{29}$ The Patient Register was initiated in 1977 and covered inpatient contacts in somatic wards. From 1995 onwards, all outpatient activities, emergency room contacts and activities in psychiatric wards were also recorded, and from 2003 it became mandatory for private hospitals and clinics to report to the register. ${ }^{30}$ The Death Register was initiated in 1975 and covers all deaths. ${ }^{31}$ The Prescription Registry covers information on all prescribed drugs sold in Denmark since $1994 .{ }^{32}$

Dementia diagnoses were made based on WHO International Classification of Disease (ICD) criteria, that is, ICD-8 in 1970-1993 and ICD-10 from 1994 onwards. There is a general underreporting of dementia. ${ }^{33}$ Once being registered, however, a dementia diagnosis in the Patient Register and Psychiatric Register has a positive predictive value of $86 \%{ }^{26}$ The validity of the dementia diagnoses in the Death Register has not been examined. The dementia outcome was defined as being registered with one of the following diagnostic codes: AD (ICD8:290.10; ICD-10:F00.0-9, G30.0-9), vascular dementia (ICD-8:293.09-19; ICD-10:F01.0-9), frontotemporal dementia (ICD-8:290.11; ICD-10:F02.0), dementia with Lewy bodies (ICD-10:G31.8) and dementia without specification (ICD-8:290.09-19; ICD-10:F03.9, G31.9).

From the Prescription Register, we included information on the purchase of cholinesterase inhibitors (donepezil, galantamine and rivastigmine) and glutamate receptor antagonists (memantine), which are used in the treatment of $\mathrm{AD}$, dementia with Lewy bodies and dementia in Parkinson's disease. In Denmark, the patient has to be given a dementia diagnosis by a specialist in psychiatry, neurology or geriatrics to get the costs of these medications reimbursed by the government. 


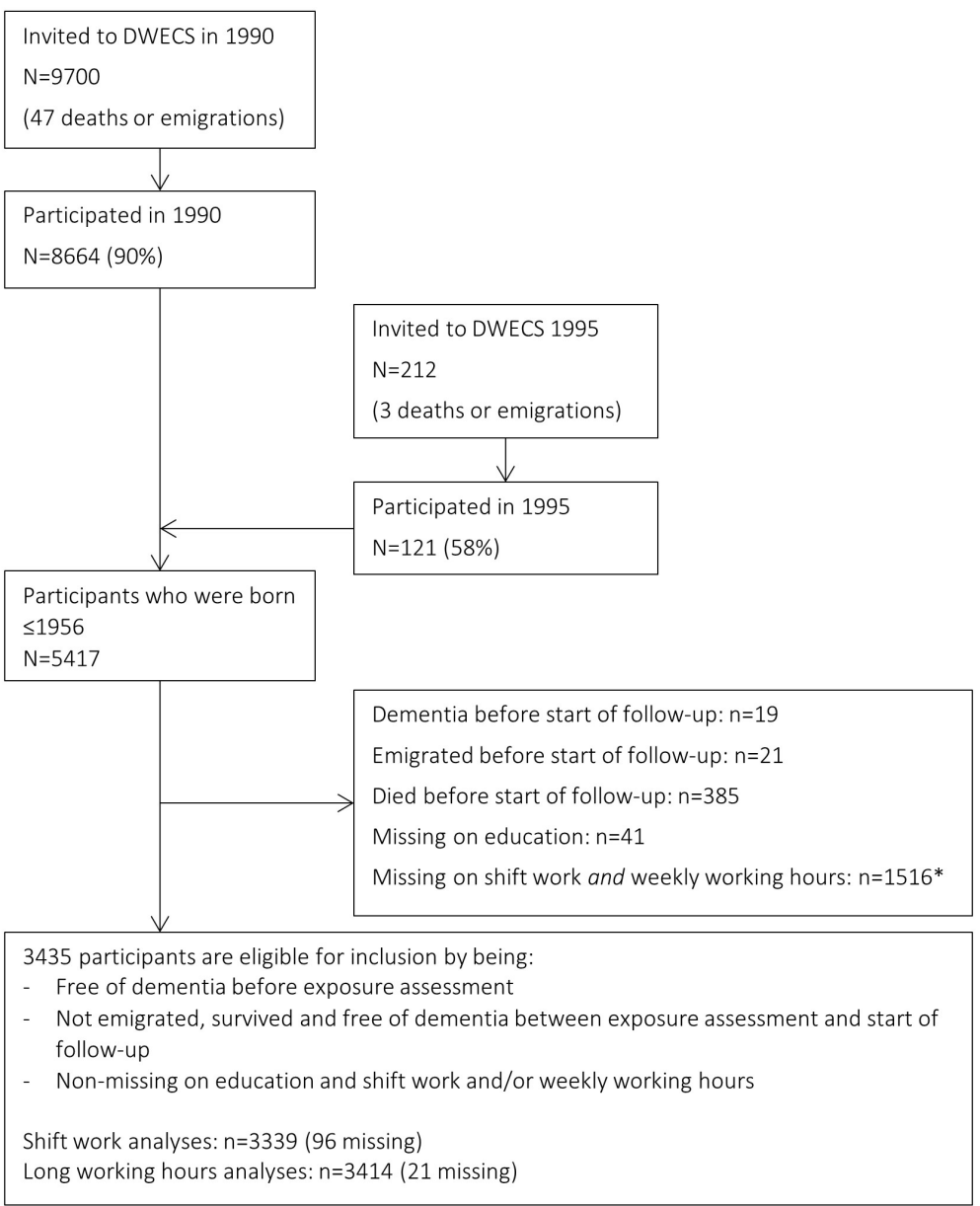

Figure 1 Flow chart of the selection of participants into the study. * $59 \%$ of these were out of the labour market at the time of the survey and $40 \%$ were self-employed or assisting spouse. DWECS, Danish Work Environment Cohort Study.

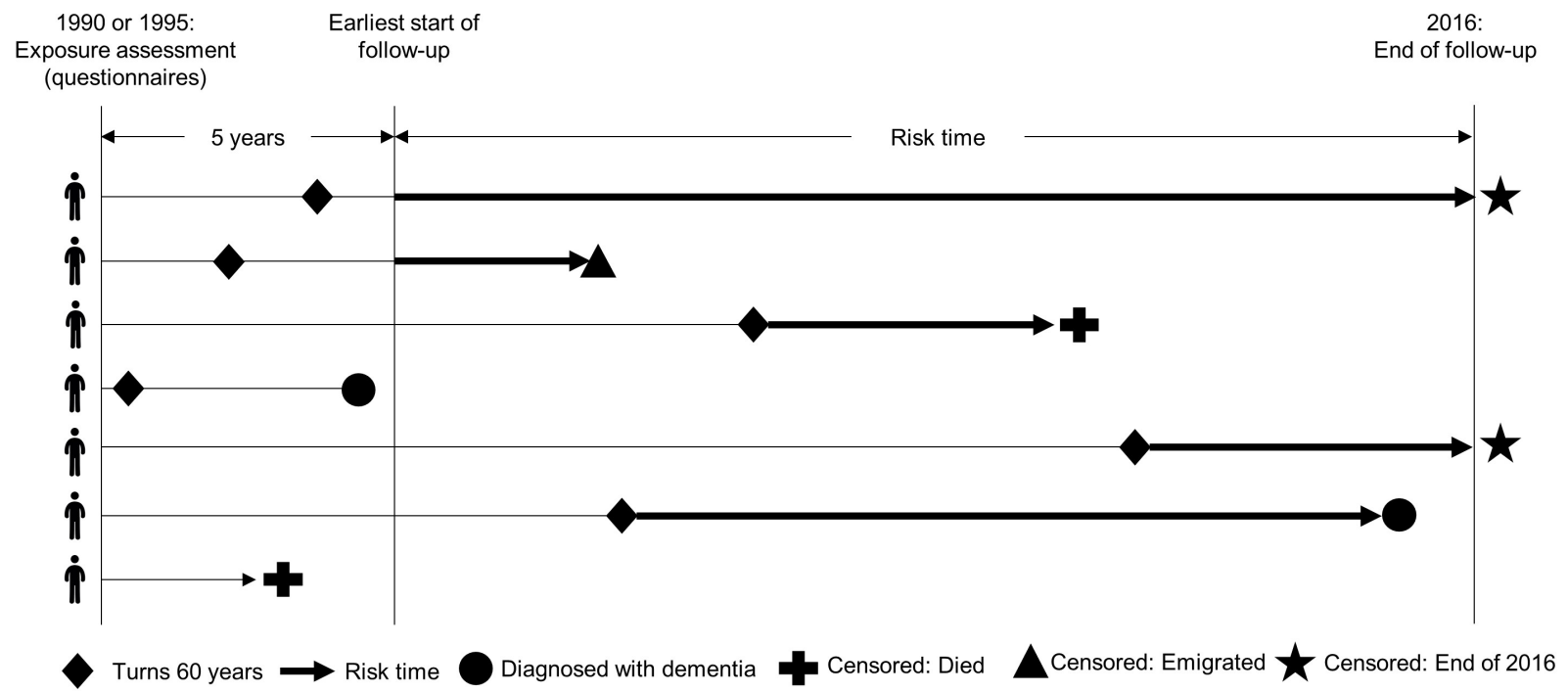

Figure 2 The design of the study, including time of exposure assessment, start of follow-up and illustration of inclusion of risk time. 
Assessment of shift work and number of weekly working hours

In 1990 or 1995, participants responded to the question: 'How are your usual working hours in your main occupation?' The response options were (a) permanent day work, (b) two-shift work, (c) three-shift work with rotating shifts, (d) three-shift work with variable shifts, (e) irregular working hours during the 24-h day or week, (f) permanent evening work, (g) permanent night work, (h) morning work and (i) other. In 1995, response options (c) and (d) were merged into three-shift work. We excluded participants responding 'other' (i) from the analyses ( $n=16$ of those otherwise eligible for inclusion). The shift work variable was categorised into 'day work' (a), 'shift work without/with unknown exposure to night work' (b, e, f, h) and 'night shift work' (c, d, g). In post hoc analyses, we divided the group of night shift workers into three-shift workers and permanent night workers.

In 1990 or 1995, the participants also reported how many hours per week they were usually working in their main occupation and in their second job. In Denmark, the standard weekly working hours have been 37 hours since $1990 .^{34}$ In this sample, $49 \%$ of the participants worked 37 hours/week. The remaining participants were divided into four groups of approximately equal size: $\leq 27$ hours/ week; $>27$ and $<37$ hours/week; $>37$ and $<45$ hours/week; $\geq 45$ hours/weeek.

\section{Covariates}

We included information about sex, age, time since exposure assessment and calendar year in two groups (1995-2005 and 2006-2016). Socioeconomic position was operationalised as the duration of vocational education (no vocational education, basic vocational education, skilled or short vocational education, 3-4 years of vocational education and more than 4 years of vocational education).

We also adjusted for psychosocial work factors (including an indicator of disturbed sleep due to rumination about work) and lifestyle-related cardiovascular risk factors. These analyses can be considered as conservative as these covariates may be confounders as well as mediators in the exposure-disease relation. ${ }^{535}$ Cardiovascular and cerebrovascular disease assessed before baseline was very seldom in this population $(1.14 \%$ of the population, none among night shift workers and $<2 \%$ among those with long working hours). Therefore, we did not adjust for this variable in our analyses.

Psychosocial work factors were assessed as 'rumination about work' (Do you have difficulties falling asleep, because of ruminations about your work?), 'influence at work' (Are you participating in the organisation of your own work, for example, what should be done, how it should be done or who you are going to collaborate with?) and 'possibilities for development' (Is it possible for you to learn something new and improve your skills?). Response options for these three questions were always, usually, usually not and never.
Among the lifestyle-related cardiovascular risk factors, we had access to information about smoking (Do you smoke? Response options: 'Yes', 'Have smoked but do not smoke anymore', 'Have never smoked'), self-reported hypertension (Has a doctor told you that you have hypertension? Response options: 'Yes', 'No') and body mass index (BMI, calculated based on self-reported weight $[\mathrm{kg}]$ divided by squared self-reported height $[\mathrm{m}]$ ). Participants were also asked when they had last been drinking alcohol (beer, wine or spirits) apart from the day of the interview. Overall, day workers and those with the longest working hours were more likely to have been drinking alcohol the day before, but data did not allow us to specify the amount and type of alcohol that was consumed and this variable was not included in the statistical analyses.

\section{Statistical analyses}

Individual follow-up time was stratified by age and calendar year into an event-time table and the association between shift work/weekly working hours and dementia was analysed using Poisson regression. ${ }^{36}{ }^{37}$ Results are presented as incidence rate ratios (IRR) and 95\% CI.

In model 1 (main analyses), we adjusted for sex, age, time since exposure assessment, calendar year and duration of vocational education. In the supplementary model 2, we added psychosocial work factors (continuous variables). In the supplementary model 3 , we added smoking (categorical), BMI (continuous), and hypertension (categorical).

There was minimal loss to follow-up as registration in the Danish national registers is mandatory, and only 11 participants emigrated before the end of follow-up. The few participants with missing data in the supplementary analyses $(\mathrm{n} \leq 36)$ were excluded analysis by analysis. All analyses were conducted using SAS V.9.2.

\section{RESULTS}

During a mean follow-up (from the age of 60) of 9.8 years, we registered 83 cases of dementia among the participants available for the analyses of shift work and 85 cases of dementia among the participants available for the analyses of long working hours. Compared with day workers (table 1), night shift workers were more often females, more frequently reported having no/short vocational education, had lower influence and possibilities for development at work, and were more frequently smokers. Night shift workers reported hypertension less frequently than day workers did.

Compared with participants working 37 hours/week (table 1), those with longer weekly working hours were more often males, more frequently had a long vocational education, were ruminating about work, had high influence and possibilities for development, had hypertension, and were less frequently smokers.

Overall, the positive association between night shift work and the risk of dementia was statistically insignificant $(I R R=2.01 ; 95 \%$ CI: 0.87-4.65). Shift work without 
Table 1 Baseline characteristics of participants according to their exposure to shift work and number of weekly working hours.

\begin{tabular}{|c|c|c|c|c|c|c|c|c|}
\hline & \multicolumn{3}{|l|}{ Shift work } & \multicolumn{5}{|c|}{ Working hours (hours/week) } \\
\hline & $\begin{array}{l}\text { Day work } \\
n=2828\end{array}$ & $\begin{array}{l}\text { Shift work } \\
\text { (-night } \\
\text { work) } \\
\mathrm{n}=396\end{array}$ & $\begin{array}{l}\text { Shift work } \\
\text { (+night work) } \\
n=115^{*}\end{array}$ & $\begin{array}{l}37 \\
n=1689\end{array}$ & $\begin{array}{l}\leq 27 \\
n=436\end{array}$ & $\begin{array}{l}28-36 \\
n=455\end{array}$ & $\begin{array}{l}38-44 \\
n=381\end{array}$ & $\begin{array}{l}\geq 45 \\
n=453\end{array}$ \\
\hline Gender (female) & $50.2 \%$ & $49.5 \%$ & $56.5 \%$ & $41.4 \%$ & $93.6 \%$ & $85.1 \%$ & $29.7 \%$ & $22.7 \%$ \\
\hline $\begin{array}{l}\text { Age at exposure } \\
\text { assessment (mean, SD) }\end{array}$ & $45.6(7.1)$ & $45.1(6.9)$ & $45.4(7.6)$ & $45.5(7.2)$ & $47.3(7.0)$ & $45.4(6.9)$ & $45.1(7.0)$ & $44.3(6.7)$ \\
\hline \multicolumn{9}{|l|}{$\begin{array}{l}\text { Duration of vocational } \\
\text { education }\end{array}$} \\
\hline No education & $17.6 \%$ & $22.5 \%$ & $24.4 \%$ & $17.9 \%$ & $25.9 \%$ & $22.4 \%$ & $13.9 \%$ & $13.5 \%$ \\
\hline Basic & $13.2 \%$ & $18.9 \%$ & $25.2 \%$ & $13.9 \%$ & $18.6 \%$ & $21.8 \%$ & $8.7 \%$ & $9.9 \%$ \\
\hline Skilled/short & $38.5 \%$ & $32.8 \%$ & $33.9 \%$ & $42.2 \%$ & $30.1 \%$ & $27.9 \%$ & $34.9 \%$ & $39.3 \%$ \\
\hline $3-4$ years or $>4$ years $\dagger$ & $30.7 \%$ & $25.8 \%$ & $16.5 \%$ & $26.0 \%$ & $25.5 \%$ & $27.9 \%$ & $42.5 \%$ & $37.5 \%$ \\
\hline $\begin{array}{l}\text { Ruminated about } \\
\text { work } \neq\end{array}$ & $5.8 \%$ & $8.6 \%$ & $7.9 \%$ & $5.2 \%$ & $6.9 \%$ & $6.6 \%$ & $6.6 \%$ & $9.1 \%$ \\
\hline Had influence at work $\ddagger$ & $87.9 \%$ & $75.8 \%$ & $69.6 \%$ & $83.4 \%$ & $84.0 \%$ & $85.5 \%$ & $90.3 \%$ & $94.0 \%$ \\
\hline $\begin{array}{l}\text { Had possibilities for } \\
\text { development } \neq\end{array}$ & $71.7 \%$ & $64.4 \%$ & $67.8 \%$ & $70.0 \%$ & $60.3 \%$ & $68.5 \%$ & $77.2 \%$ & $79.8 \%$ \\
\hline \multicolumn{9}{|l|}{ Smoking } \\
\hline Never & $31.3 \%$ & $28.5 \%$ & $20.9 \%$ & $28.8 \%$ & $38.3 \%$ & $32.1 \%$ & $27.0 \%$ & $29.6 \%$ \\
\hline Previously & $22.3 \%$ & $17.2 \%$ & $19.1 \%$ & $20.1 \%$ & $19.3 \%$ & $22.6 \%$ & $26.3 \%$ & $24.3 \%$ \\
\hline Yes & $46.4 \%$ & $54.3 \%$ & $60.0 \%$ & $51.2 \%$ & $42.4 \%$ & $45.3 \%$ & $46.7 \%$ & $46.1 \%$ \\
\hline BMI (mean, SD) & $23.9(3.4)$ & $24.6(4.0)$ & $24.2(3.6)$ & $24.2(3.5)$ & $22.9(3.5)$ & $23.1(3.6)$ & $24.6(3.6)$ & $24.7(3.3)$ \\
\hline Hypertension (yes) & $7.8 \%$ & $8.4 \%$ & $4.4 \%$ & $6.7 \%$ & $9.9 \%$ & $7.9 \%$ & $7.6 \%$ & $9.1 \%$ \\
\hline \multicolumn{9}{|l|}{ Work schedule } \\
\hline Day work & & & & $86.9 \%$ & $81.4 \%$ & $76.3 \%$ & $87.1 \%$ & $87.9 \%$ \\
\hline Shift work (-night work) & & & & $10.5 \%$ & $16.0 \%$ & $14.2 \%$ & $10.2 \%$ & $10.2 \%$ \\
\hline Shift work (+night work) & & & & $2.6 \%$ & $2.6 \%$ & $9.5 \%$ & $2.7 \%$ & $1.9 \%$ \\
\hline \multicolumn{9}{|l|}{ Weekly working hours } \\
\hline 37 & $51.3 \%$ & $45.2 \%$ & $38.3 \%$ & & & & & \\
\hline$\leq 27$ & $12.1 \%$ & $17.4 \%$ & $9.6 \%$ & & & & & \\
\hline $28-36$ & $12.0 \%$ & $16.4 \%$ & $36.5 \%$ & & & & & \\
\hline $38-44$ & $11.5 \%$ & $9.9 \%$ & $8.7 \%$ & & & & & \\
\hline$\geq 45$ & $13.1 \%$ & $11.2 \%$ & $7.0 \%$ & & & & & \\
\hline
\end{tabular}

*Three-shift workers: $\mathrm{n}=54$; permanent night workers: $\mathrm{n}=61$.

†3-4 years and $>4$ years are grouped together in the descriptive analyses in order to adhere to the rules regarding data confidentiality. ‡Usually/always.

BMI, body mass index.

night work was not associated with a higher incidence of dementia. Post hoc analyses revealed that the risk appeared to highest among the permanent night workers (IRR=3.25; 95\% CI: 1.35-7.83). The risk among the group of three-shift workers could not be reliably estimated due to lack of statistical power.

We also found that the risk of dementia was higher among participants working 38-44hours/week (IRR=2.08; 95\% CI: 1.11-3.90) compared with those working 37 hours/ week. Shorter weekly working hours ( $\leq 27$ or $28-36$ hours/ week) or the longest weekly working hours ( $\geq 45$ hours/ week) were not associated with dementia.

In supplementary analyses, none of the findings were substantially changed by adjustment for psychosocial work factors (model 2) or lifestyle-related cardiovascular risk factors (model 3) (table 2). Furthermore, when mutually adjusted, the IRR for dementia was 1.96 (95\% CI: 1.02-3.75) among those working 38-45 hours/week and 1.76 (95\% CI: 0.74-4.15) among night shift workers (also adjusted for gender, age, time since exposure assessment, 
Table 2 The association between shift work/number of weekly working hours and the incidence of dementia. Associations are expressed as IRR and their $95 \%$ Cls.

\begin{tabular}{|c|c|c|c|c|c|c|c|c|}
\hline & \multirow{2}{*}{$\begin{array}{l}\text { Dementia } \\
\text { cases }\end{array}$} & \multirow{2}{*}{$\begin{array}{l}\text { Person- } \\
\text { years }\end{array}$} & \multicolumn{2}{|c|}{$\begin{array}{l}\text { Model } 1 \\
\text { (main analysis) }\end{array}$} & \multicolumn{2}{|c|}{$\begin{array}{l}\text { Model } 2 \\
\text { (supplementary analysis) }\end{array}$} & \multicolumn{2}{|c|}{$\begin{array}{l}\text { Model } 3 \\
\text { (supplementary analysis) }\end{array}$} \\
\hline & & & IRR & $95 \% \mathrm{Cl}$ & IRR & $95 \% \mathrm{Cl}$ & & \\
\hline Day work (reference) & 69 & 27975 & 1.00 & & 1.00 & & 1.00 & \\
\hline Shift work (-night work) & 8 & 3828 & 0.90 & 0.44 to 1.85 & 0.81 & 0.39 to 1.68 & 0.88 & 0.42 to 1.84 \\
\hline Shift work (+night work) ${ }^{*}$ & 6 & 1056 & 2.01 & 0.87 to 4.65 & 1.92 & 0.81 to 4.57 & 2.11 & 0.92 to 4.85 \\
\hline 37 hours/week (reference) & 37 & 16280 & 1.00 & & 1.00 & & 1.00 & \\
\hline$\leq 27$ hours/week & 12 & 4983 & 1.13 & 0.53 to 2.43 & 1.13 & 0.53 to 2.40 & 1.13 & 0.53 to 2.42 \\
\hline 28-36 hours/week & 14 & 4539 & 1.77 & 0.90 to 3.49 & 1.69 & 0.87 to 3.29 & 1.70 & 0.86 to 3.36 \\
\hline 38-44 hours/week & 14 & 3549 & 2.08 & 1.11 to 3.90 & 2.05 & 1.08 to 3.89 & 1.98 & 1.03 to 3.79 \\
\hline
\end{tabular}

Model 1: Gender, age, time since exposure assessment, calendar year and duration of vocational education. Model 2: Model $1+$ ruminations about work, influence at work and possibilities for development. Model 3: Model $1+$ smoking, BMI and hypertension.

*Permanent night work analysed separately: IRR=3.25; $95 \% \mathrm{Cl} 1.35$ to 7.83 (model 1), IRR=3.48; $95 \% \mathrm{Cl} 1.45$ to 8.35 (model 2), IRR=3.62, $95 \% \mathrm{Cl} 1.53$ to 8.55 (model 3).

IRR, incidence rate ratios.

calendar year and duration of vocational education, data not shown in tables).

Recent studies have shown a negative effect of multiple jobs holding on sleep duration. ${ }^{38}$ Among employees working 37 hours/week, less than $1 \%$ had a secondary job, while $32 \%$ of those working 38-44hours/week and $29 \%$ of those working $\geq 45$ hours/week had a secondary job. Yet, adjustment for multiple jobs holding did not change the findings of the association between dementia and weekly working hours.

\section{DISCUSSION}

\section{Main findings}

Our study did not find shift work encompassing night work to be associated with a higher risk of dementia. Neither did we find a consistent association between long working hours and dementia. However, we found a statistically, significantly higher incidence of dementia in a subgroup of permanent night workers and among participants with moderately longer weekly working hours (38-44 hours/ week). The estimated differences were not explained by differences in baseline duration of vocational education, psychosocial work factors and lifestyle-related cardiovascular risk factors.

\section{Comparison with previous research}

If night shift work increases the risk of dementia, we would expect the risk of dementia to be moderately higher among three-shift workers and even more among permanent night workers compared with non-night shift workers and day workers. Unfortunately, there were too few cases among participants with three-shift work to analyse this subgroup separately. Previously, a higher dementia-related mortality was found among rotating shift workers with or without night shifts and permanent evening workers. ${ }^{21}$ In addition, a recent study showed that exposure to more than 20 years of night shift work was associated with a higher incidence of dementia, but only in APOE $\varepsilon 4$-carriers. ${ }^{22}$ In the present study, we did not find a higher dementia risk among shift workers without night work. In addition, two previous studies did not find a higher dementia risk among shift or night workers (no further specification of the exposure) ${ }^{2324}$ Thus, merging shift workers into one group encompassing different types of unspecified shift schedules may cause inconclusive findings regarding the potential effect of specific types of shift work on cognitive health outcomes.

Night shift work may influence the risk of dementia, but cognitive function may also determine selection into job types encompassing certain work schedules. Two studies found that current night shift work and unspecified shift work were associated with poorer cognitive performance and that those with recent shift work experience had poorer cognitive performance than those who ceased working shifts 5-10 years ago. ${ }^{40}{ }^{41}$ In contrast, two other studies found no differences in cognitive functioning in late life or at retirement and no difference in the rate of cognitive decline when comparing nurses with and without night shift work ${ }^{42}$ or Swedish twins with and without a history of unspecified shift work. ${ }^{43}$ In the latter study, shift workers with short education showed better cognitive function at baseline than day workers with short education. Thus, although selection processes into and out of shift work are likely to occur, the direction of these is complex.

The only previous study on long working hours and dementia found no association between working $\geq 45$ hours/week and the risk of dementia. ${ }^{24}$ As 
with shift work, cognitive function may determine selection into job types with longer or shorter working hours. One study among nurses found that long working hours (41-55 and $>55$ hours/week) was cross-sectionally associated with lower cognitive performance and longitudinally associated with a decline in performance. ${ }^{44}$ Another study among automotive workers reported that working overtime ( $>40$ hours/week) before the test day was associated with poorer cognitive performance. ${ }^{45}$ Thus, it appears that there is some evidence for an association of long working hours with poor cognitive function. Importantly, however, we did not find a dose-response relationship between duration of working hours and dementia. Furthermore, in some countries, 38-44 hours are not even considered long working hours. If we do assume that long working hours affect the risk of dementia, eg, through sleep deprivation and cardiovascular risk factors, ${ }^{695}$ strong compensatory mechanisms, eg, high levels of job complexity, must be at play in employees holding job with the longest working hours ( $\geq 45$ hours/week).

\section{Strengths and limitations}

The strengths of the present study are that we use a longitudinal design with prospective collection of data on shift work and weekly working hours. We also use data on dementia diagnoses from national registers, which contributes to the validity of the outcome measure. ${ }^{26}$ Yet, we did not analyse the subtypes of dementia, for example, AD. First, the validity of the subtypes in the Danish registers seems to be poor. ${ }^{26}$ Second, we did not hypothesise that the effect of night shift work was restricted to one specific dementia subtype. Third, the statistical power of our study did not allow for more nuanced analyses. The use of a register-based outcome has the advantage of a negligible loss to follow-up, although there is an underreporting of dementia in the general population. ${ }^{33}$ Indeed, even when taking into account that the maximum age at the end of follow-up of the included participants, the dementia incidence seemed to be relatively low (2.5 per 1000 person-years) compared with the corresponding figures for Western Europe (60-64 years old: 3.1; 65-69 years old: $5.3 ; 70-79$ years old: 9.3$){ }^{46}$ As we only included participants who were employed at the time of the exposure assessment, our sample is likely to be healthier than the Danish population in general. In addition, under-diagnosis or diagnosis made in primary care, which is not captured in the national registers, may contribute to the observed incidence rate. Importantly, if the degree of underreporting (misclassification) is associated with shift work or weekly working hours, our estimates are potentially biased. On the one hand, holding a long education is associated with a lower risk of passing the 'threshold' of dementia, given the same absolute decrease in cognitive function. ${ }^{478}$ On the other hand, higher educational level may positively influence treatment-seeking behaviour. Thus, although the estimates presented in this study are adjusted for duration of vocational education, it is unlikely that this adjustment fully handles the complex processes leading from signs of cognitive decline to actually ending up being registered with dementia.

We handle reverse causation by starting our follow-up period (at least) 5 years after the exposure assessment. By doing so, we have reduced the influence of cognitive decline on the choice of working hours. Confounding was handled by adjustment for sex, age and the duration of vocational education. In supplementary analyses, we examined the influence of psychosocial work factors and lifestyle-related cardiovascular risk factors for the investigated associations. None of the covariates substantially changed the estimates.

Still, we cannot rule out that these results are chance findings or that the estimated differences are biased by unmeasured confounding factors determining selection into specific job types with permanent night work or moderately longer working hours. Unmeasured confounders that may explain the differences in dementia risk among those working 38-44hours/week and those working $\geq 45$ hours/week could be cognitive function at baseline, sleep need, reactivity to stress or coping style. In future studies, information about such factors could contribute to the understanding of why some individuals work long hours without negative health outcomes.

Using a sample from the general working population enhances, to some extent, the generalisability of the findings, but at the cost of a higher risk of unmeasured confounders related to work-related exposures, especially because some sectors and job types are characterised by 24 hours service and thereby shift work, whereas others primarily operate during the day. Likewise, working shorter or longer working hours is also closely related to sector and job type. Studying specific occupational groups, for example, within the police, manufacturing, service or healthcare sector would constitute a way forward. Our assessment of the exposure to shift work allowed us to differentiate between shift workers with and without night work, but we did not have information about for how many years the participants were exposed to specific work schedules. Furthermore, our analyses revealed a small total number of cases due to the relatively young cohort, and therefore performing more nuanced subgroup analyses was not feasible within this study.

\section{CONCLUSION}

We did not find arguments that night shift work in general is associated with a higher risk of dementia. Yet, we did find a higher incidence of dementia in a subgroup of permanent night workers. Additionally, our hypothesis of an effect of long working hours on the risk of dementia was not supported, in particular, because we did not find any indication of a dose-response relationship between the number of weekly working hours and dementia. A subgroup of employees with moderately longer than the standard weekly working hours had a higher risk of dementia. Yet, this finding may be very context specific, as 
working 38-44hours/week may not be considered long working hours in other countries.

The study suffered from insufficient statistical power due to the small number of participants exposed to night work and the low number of dementia cases. Therefore, this is a cautious conclusion, which needs to be substantiated in future studies.

Contributors KN-N, AHG, FG, ELM, TKTP, NHR, GW and ÅMH conceived and designed the study. KN-N and KI-A conducted the data analyses. KN-N, ÅMH, KI-A, MBG, FG, SI, ELM, TKTP, NHR, GW, RGJW and AHG interpreted the results. KN-N drafted the article. KN-N, ÅMH, KI-A, MBG, FG, SI, ELM, TKTP, NHR, GW, RGJW and AHG critically revised the article. KN-N, ÅMH, KI-A, MBG, FG, SI, ELM, TKTP, NHR, GW, RGJW and AHG gave the final approval for the version to be published.

Funding This study was supported by a grant from The Danish Working Environment Research Fund (10- 2015-03 20150017498). The fund has not had any influence on the design of the study, statistical analyses, interpretation of the findings or the conclusion of this study.

Competing interests None declared.

Patient consent for publication Not required.

Ethics approval The study has been notified to the Danish data protection authorities and adheres to the regulations that ensure the protection of personal data. According to the Danish legislation, this study did not need approval from the local Committee for Health Research Ethics.

Provenance and peer review Not commissioned; externally peer reviewed.

Data sharing statement Deidentified participant data from the DWECS survey may under certain conditions be available from The National Research Centre for the Working Environment,Copenhagen, Denmark (contact: nfa@nfa.dk).

Open access This is an open access article distributed in accordance with the Creative Commons Attribution Non Commercial (CC BY-NC 4.0) license, which permits others to distribute, remix, adapt, build upon this work non-commercially, and license their derivative works on different terms, provided the original work is properly cited, appropriate credit is given, any changes made indicated, and the use is non-commercial. See: http://creativecommons.org/licenses/by-nc/4.0/.

\section{REFERENCES}

1. Winblad B, Amouyel P, Andrieu S, et al. Defeating Alzheimer's disease and other dementias: a priority for European science and society. Lancet Neurol 2016;15:455-532.

2. Raz L, Knoefel J, Bhaskar K. The neuropathology and cerebrovascular mechanisms of dementia. Journal of Cerebral Blood Flow \& Metabolism 2016;36:172-86.

3. Beydoun MA, Beydoun HA, Gamaldo AA, et al. Epidemiologic studies of modifiable factors associated with cognition and dementia: systematic review and meta-analysis. BMC Public Health 2014;14:643.

4. Mangialasche F, Kivipelto M, Solomon A, et al. Dementia prevention: current epidemiological evidence and future perspective. Alzheimers Res Ther 2012;4:6.

5. Puttonen S, Härmä M, Hublin C. Shift work and cardiovascular disease - pathways from circadian stress to morbidity. Scand J Work Environ Health 2010;36:96-108.

6. van der Hulst M. Long workhours and health. Scand J Work Environ Health 2003;29:171-88.

7. Ju YE, Lucey BP, Holtzman DM. Sleep and Alzheimer disease pathology--a bidirectional relationship. Nat Rev Neurol 2014;10:115-9.

8. Sallinen M, Kecklund G. Shift work, sleep, and sleepiness differences between shift schedules and systems. Scand J Work Environ Health 2010;36:121-33.

9. Virtanen M, Ferrie JE, Gimeno D, et al. Long working hours and sleep disturbances: the Whitehall II prospective cohort study. Sleep 2009;32:737-45

10. Xie L, Kang H, Xu Q, et al. Sleep drives metabolite clearance from the adult brain. Science 2013;342:373-7.

11. Ju YS, Ooms SJ, Sutphen C, et al. Slow wave sleep disruption increases cerebrospinal fluid amyloid- $\beta$ levels. Brain 2017;140:2104-11.
12. Sindi S, Johansson L, Skoog J, et al. Sleep disturbances and later cognitive status: a multi-centre study. Sleep Med 2018;52:26-33.

13. Bokenberger K, Ström P, Dahl Aslan AK, et al. Association Between Sleep Characteristics and Incident Dementia Accounting for Baseline Cognitive Status: A Prospective Population-Based Study. J Gerontol A Biol Sci Med Sci 2017;72.

14. Luojus MK, Lehto SM, Tolmunen T, et al. Self-reported sleep disturbance and incidence of dementia in ageing men. J Epidemiol Community Health 2017;71:329-35.

15. Benedict C, Byberg L, Cedernaes J, et al. Self-reported sleep disturbance is associated with Alzheimer's disease risk in men. Alzheimers Dement 2015;11:1090-7.

16. Bøggild $\mathrm{H}$, Burr $\mathrm{H}$, Tüchsen $\mathrm{F}$, et al. Work environment of Danish shift and day workers. Scand J Work Environ Health 2001;27:97-105.

17. Johnson JV, Lipscomb J, hours Lworking. Long working hours, occupational health and the changing nature of work organization. Am J Ind Med 2006;49:921-9.

18. Nabe-Nielsen K, Tüchsen F, Christensen KB, et al. Differences between day and nonday workers in exposure to physical and psychosocial work factors in the Danish eldercare sector. Scand J Work Environ Health 2009;35:48-55.

19. Then FS, Luck T, Luppa M, et al. Systematic review of the effect of the psychosocial working environment on cognition and dementia. Occup Environ Med 2014;71:358-65.

20. Nexø MA, Meng A, Borg V. Can psychosocial work conditions protect against age-related cognitive decline? Results from a systematic review. Occup Environ Med 2016;73:487-96.

21. Jørgensen JT, Karlsen S, Stayner L, et al. Shift work and overall and cause-specific mortality in the Danish nurse cohort. Scand J Work Environ Health 2017;43:117-26.

22. Bokenberger K, Sjölander A, Dahl Aslan AK, et al. Shift work and risk of incident dementia: a study of two population-based cohorts. Eur J Epidemiol 2018;33:977-87.

23. Seidler A, Nienhaus A, Bernhardt T, et al. Psychosocial work factors and dementia. Occup Environ Med 2004;61:962-71.

24. Nabe-Nielsen K, Garde AH, Ishtiak-Ahmed K, et al. Shift work, long working hours, and later risk of dementia: A long-term follow-up of the Copenhagen Male Study. Scand J Work Environ Health 2017;43.

25. Burr H, Bjorner JB, Kristensen TS, et al. Trends in the Danish work environment in 1990-2000 and their associations with labor-force changes. Scand J Work Environ Health 2003;29:270-9.

26. Phung TK, Andersen BB, Høgh P, et al. Validity of dementia diagnoses in the Danish hospital registers. Dement Geriatr Cogn Disord 2007;24:220-8.

27. Nielsen TR, Vogel A, Phung TK, et al. Over- and under-diagnosis of dementia in ethnic minorities: a nationwide register-based study. Int $J$ Geriatr Psychiatry 2011;26:1128-35.

28. Salem LC, Andersen BB, Nielsen TR, et al. Overdiagnosis of dementia in young patients - a nationwide register-based study. Dement Geriatr Cogn Disord 2012;34:292-9.

29. Mors O, Perto GP, Mortensen PB. The Danish Psychiatric Central Research Register. Scand J Public Health 2011;39:54-7.

30. Lynge E, Sandegaard JL, Rebolj M. The Danish National Patient Register. Scand J Public Health 2011;39:30-3.

31. Helweg-Larsen K. The Danish Register of Causes of Death. Scand J Public Health 2011;39:26-9.

32. Kildemoes HW, Sørensen HT, Hallas J. The Danish National Prescription Registry. Scand J Public Health 2011;39:38-41.

33. Phung TKT, Waltoft BL, Kessing LV, et al. Is dementia underdiagnosed? A nationwide population based study of incidence and prevalence of dementia using national registers. Eur J Neurol 2008;15:35

34. Schmidt-Sørensen JB, Christiansen NF. Arbejdstid i Den Store Danske. Gyldendal 2017.

35. Bannai $A$, Tamakoshi $A$. The association between long working hours and health: a systematic review of epidemiological evidence. Scand $J$ Work Environ Health 2014;40:5-18.

36. Carstensen B. Demography and epidemiology: Practical use of the Lexis diagram in the computer age or: Who needs the Cox-model anyway? 2005:1-30.

37. Carstensen B. Age-period-cohort models for the Lexis diagram. Stat Med 2007;26:3018-45.

38. Marucci-Wellman HR, Lombardi DA, Willetts JL. Working multiple jobs over a day or a week: Short-term effects on sleep duration. Chronobiol Int 2016;33:630-49.

39. Marucci-Wellman HR, Lin TC, Willetts JL, et al. Differences in time use and activity patterns when adding a second job: implications for health and safety in the United States. Am J Public Health 2014;104:1488-500. 
40. Marquié JC, Tucker P, Folkard S, et al. Chronic effects of shift work on cognition: findings from the VISAT longitudinal study. Occup Environ Med 2015;72.

41. Titova OE, Lindberg E, Elmståhl S, et al. Association between shift work history and performance on the trail making test in middleaged and elderly humans: the EpiHealth study. Neurobiol Aging 2016;45:23-9.

42. Devore EE, Grodstein F, Schernhammer ES. Shift work and cognition in the Nurses' Health Study. Am J Epidemiol 2013;178:1296-300.

43. Bokenberger K, Ström P, Dahl Aslan AK, et al. Shift work and cognitive aging: a longitudinal study. Scand J Work Environ Health 2017;43:485-93.

44. Virtanen M, Singh-Manoux A, Ferrie JE, et al. Long Working Hours and Cognitive Function. Am J Epidemiol 2009;169:596-605.
45. Proctor SP, White RF, Robins TG, et al. Effect of overtime work on cognitive function in automotive workers. Scand $J$ Work Environ Health 1996;22:124-32.

46. Prince M, Wimo A, Guerchet M, et al. World Alzheimer Report 2015, The Global Impact of Dementia: An Analysis of Prevalence, Incidence, Costs and Trends. London: Alzheimer's Disease International 2015:1-82.

47. Meng X, D'Arcy C. Education and dementia in the context of the cognitive reserve hypothesis: a systematic review with meta-analyses and qualitative analyses. PLoS One 2012;7:e38268.

48. Lenehan ME, Summers MJ, Saunders NL, et al. Relationship between education and age-related cognitive decline: a review of recent research. Psychogeriatrics 2015;15. 